\title{
Article \\ Deformation Behavior of Saturated Soft Clay under Cyclic Loading with Principal Stress Rotation
}

\author{
Zunan Fu ${ }^{1}$, Guoshuai Wang ${ }^{2}$, Wenbo Song ${ }^{2}{ }^{(}$, Yanming Yu ${ }^{1}$, Pengfei Wei ${ }^{3, *}$ and Tingyu Wu ${ }^{3, *}$ \\ 1 Huadong Engineering Corporation Limited, Hangzhou 310000, China; fu_zn@hdec.com (Z.F.); \\ yu_ym@hdec.com (Y.Y.) \\ 2 Zhejiang Huadong Engineering Construction Management Co., Ltd., Hangzhou 310000, China; \\ wang_gs@hdec.com (G.W.); song_wb@hdec.com (W.S.) \\ 3 College of Civil Engineering, Zhejiang University of Technology, Hangzhou 310000, China \\ * Correspondence: wpffeis@gmail.com (P.W.); wutingyu@zjut.edu.cn (T.W.)
}

check for updates

Citation: Fu, Z.; Wang, G.; Song, W.; Yu, Y.; Wei, P.; Wu, T. Deformation Behavior of Saturated Soft Clay under Cyclic Loading with Principal Stress Rotation. Appl. Sci. 2021, 11, 8987. https://doi.org/10.3390/ app11198987

Academic Editor: Daniel Dias

Received: 26 August 2021

Accepted: 23 September 2021

Published: 27 September 2021

Publisher's Note: MDPI stays neutral with regard to jurisdictional claims in published maps and institutional affiliations.

Copyright: (c) 2021 by the authors. Licensee MDPI, Basel, Switzerland. This article is an open access article distributed under the terms and conditions of the Creative Commons Attribution (CC BY) license (https:/ / creativecommons.org/licenses/by/ $4.0 /)$.

\begin{abstract}
Under long-term traffic loading, the soil elements in subgrade are subjected to continuous principal stress rotation. In order to study the deformation properties of soft clays under traffic loading with principal stress rotation, a series of cyclic torsional shear tests were conducted on Wenzhou soft clays under different torsional cyclic stress ratios and degrees of principal stress rotation. The test results showed the stiffness softening of soil under long-term traffic loading. In addition, the principal stress rotation induced by traffic loading aggravated the deformation of clay samples and pore pressure accumulation. A modified dynamic pore pressure model was applied to consider the effect of principal stress rotation on undrained cumulative pore pressure, predicting the growth of cumulative pore pressure at different cycles. Considering loading cycles and the principal stress rotation, a modified Hardin-Drnevich (H-D) backbone curve model under traffic loading with principal stress rotation was proposed, and the predictive values of this model agreed well with the experimental values. Compared with the traditional $\mathrm{H}-\mathrm{D}$ model, this model better reflects the cyclic deformation of soft clays under long-term traffic loading with principal stress rotation.
\end{abstract}

Keywords: soft clay; traffic loading; principal stress rotation; dynamic hollow cylinder apparatus; backbone curve

\section{Introduction}

Wenzhou soft clay is a typical soft clay. It has a high water content, low shearing strength, low permeability, and high compressibility. The soft clay was formed in the late Quaternary period and is widely distributed in the coastal areas of China [1]. In this region, rapid economic development has led to a significant increase in transportation construction, most of which is built on the soft ground. The traffic loading exerted by the transportation is a typical cyclic loading. Under the long-term action of traffic loading, the soil structure under the subgrade is disturbed, easily producing deformation, stability reduction, and other problems. The soft clay has poor engineering properties and is more sensitive to disturbance [2]. Therefore, to improve the service performance of traffic facilities in coastal areas and to control the maintenance costs, it is necessary to study the cyclic behavior of saturated soft clay under traffic loading.

During a certain vehicle wheel passing, the changes in the stress components of the soil element in subgrade are more complex. As shown in Figure 1, the vertical cyclic stress $\sigma_{11}$, the horizontal cyclic stress $\sigma_{22}$, and the shear stress $\tau_{12}$ are constantly changing, and the shear stress $\tau_{12}$ changes both in magnitude and direction. Therefore, the principal stress axis on the soil element rotates continuously [3,4]. The stress path of the traffic loading in the $\sigma-\tau$ plane can be simplified as a cardioid (see Figure 2). According to Powrie et al. [5], the shear stress in subgrade decays faster with depth than the normal stresses do. Therefore, the ratio of shear stress to axial stress of the soil under traffic loading decreases with depth, 
i.e., the degrees of principal stress rotation in the soil at different depths are different. In recent years, some scholars have carried out a series of studies on the rotation of the principal stress axis for soft clay. However, there is comparatively little research on the deformation characteristics of soft clay.

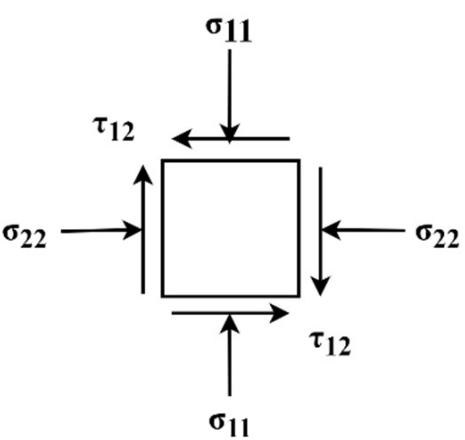

$\boldsymbol{\sigma}_{11}$ : Vetical normal stress

$\boldsymbol{\sigma}_{22}$ : Horizontal normal stress

$\tau_{12}$ : Shear stress
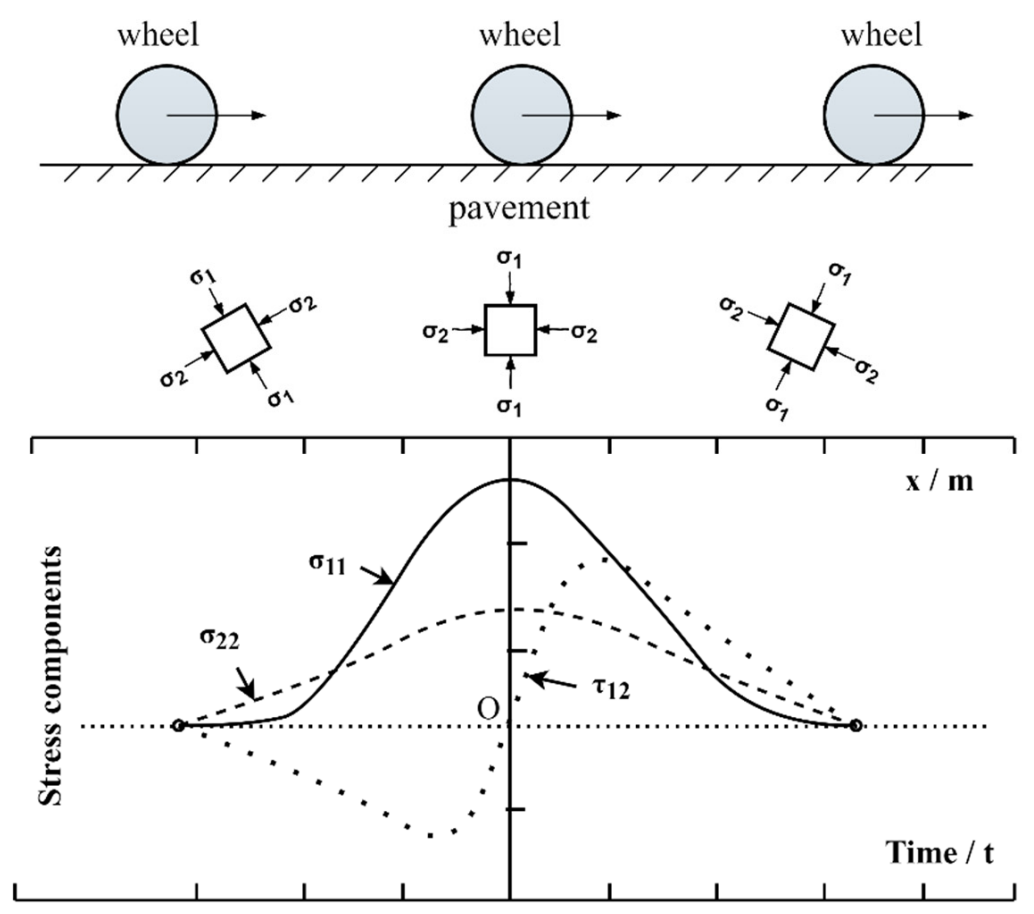

Figure 1. Stress components of soil element in soft subgrade induced by traffic loading.

Pavement

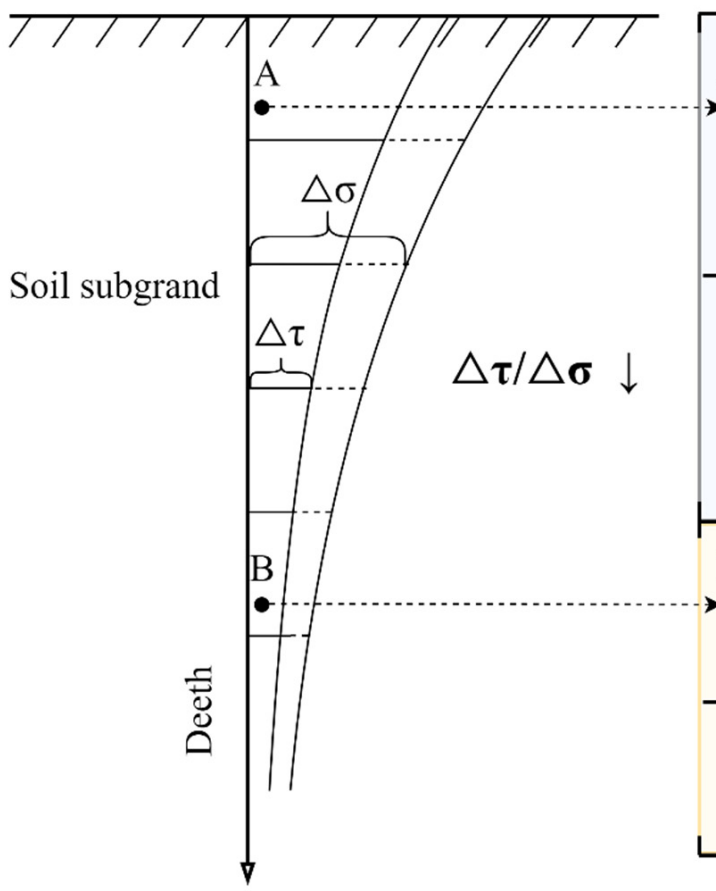

Cardioid stress path

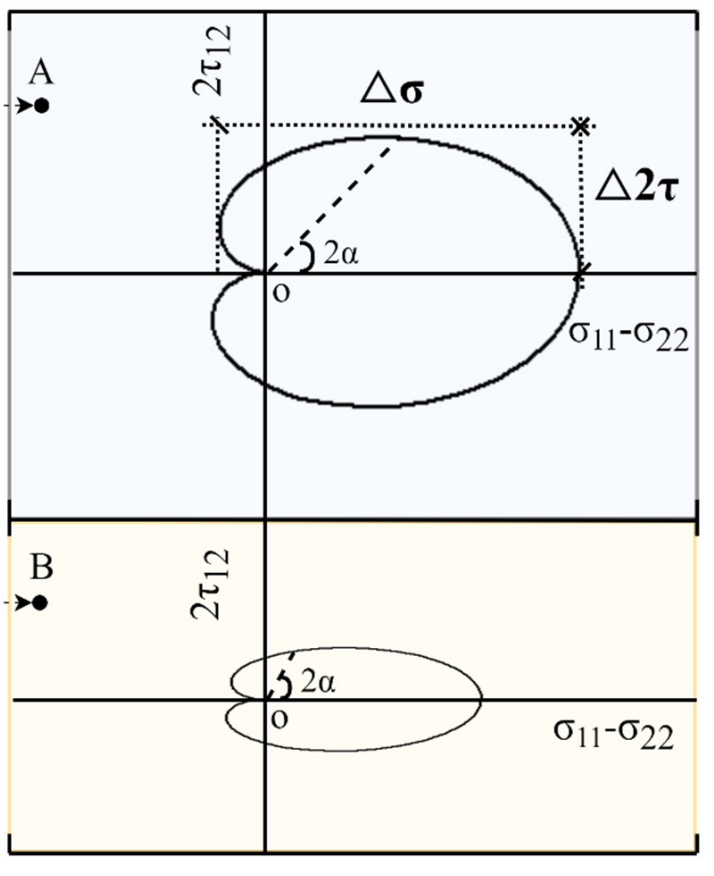

Figure 2. Schematic diagram of degradation of soil stress with depth. 
Soil dynamics is one of the most popular studies in soil mechanics. Many researchers have researched the factors that may affect the dynamic characteristics of soil, such as the frequency, loading rate, amplitude, overconsolidation ratio, and loading times. Some scholars believe that low-frequency cyclic loading can better reflect the actual situation of soil, and the pore pressure development is more uniform [6-8]. The strain rate affects the shear strength of soil, while the loading rate affects the shear modulus of soil [9-11]. The influence of the cyclic number and overconsolidation ratio on soil dynamic characteristics has also been studied by many scholars [12-14]. The effects on the soil can be attributed to the different loading histories of soil, and different stress paths were found to be the main influence on the cyclic behavior of soil.

Pore pressure is one of the important characteristics of saturated soft clay under cyclic loading. The development of pore pressure can soften the stiffness and strength of soil, which leads to the destruction of soil structure. Many factors affect the variation in pore pressure of saturated clay under cyclic loadings, such as the cycles, the magnitude of deviator stress, cyclic stress ratio, and frequency $[15,16]$. Therefore, the cumulative pore pressure model needs to be further studied. Among the existing pore pressure models, there are many models of pore pressure for saturated clay under dynamic load, and many scholars have directly established the relationship model between pore pressure and strain $[17,18]$. These models are mainly of exponential, bilinear, and polynomial types. However, there are many factors affecting pore pressure and soil strain, and the relationship between pore pressure and strain is different under different factors. Even if a relationship between pore pressure and strain is established, the results are not universal, due to the many factors involved. Given the current state of research on pore pressure in clays, it is difficult to establish a pore pressure model that reflects the mechanism of pore pressure variation and the influence of various factors, which can only be focused on in specific situations. In order to study the influence of principal stress rotation on the pore pressure, it is necessary to introduce cycles $N$ as an objective reference quantity that does not change with various influencing factors. The relationship between the increase in pore pressure and loading cycles, taking into account the rotation of the principal stress axis, is established. The relationship between pore pressure and strain in the soil under the principal stress rotation is determined indirectly through loading cycles, which can reflect the actual situation of pore pressure and strain changes more objectively.

The backbone curve is one of the most important indicators of the nonlinear stressstrain relationship in research on the cyclic behavior of soil. Hardin et al. $[19,20]$ and Ishibashi et al. [21] gave expressions for the variation in dynamic elastic mode and dynamic damping ratio with shear stress amplitude. Sun et al. [22] found that if the stress amplitude is maintained constant, the increase in amplitude of cyclic confining pressure will promote the development of both permanent volumetric strain and axial strain significantly. Pyke et al. [23] found that the backbone curve for the stress-strain relationship in soils subjected to cyclic loading in most cases can be assumed to be a hyperbolic model. Yasuhara et al. [8], Liao et al. [24], and Zhang et al. [25] pointed out the variation in the backbone curve of soils based on the results of cyclic loading tests under different loading conditions. They gave expressions for the dynamic stress-strain relationship. Huang et al. [26] used a bidirectional triaxial apparatus to simulate traffic loading. They proposed a model for the backbone curve of soft clay in Ningbo, considering the cyclic surrounding pressure and the number of vibrations. Currently, based on the research of a large number of scholars, the backbone curve models are mainly classified into three types: Hardin-Drnevich hyperbolic model [19,20,27], Ramberg-Osgood model [6], and MartinDarvidenkov model [28]. Among them, the Hardin-Drnevich (H-D) model is commonly used to describe the dynamic properties of soft clay. In addition, the above studies are all based on triaxial test results, and the cyclic loading under the triaxial stress state does not truly reflect the rotational effect of the principal stress axis in the traffic loading. The period of the above studies is limited, and the study of soil backbone curves under long-term cyclic loading is rare. 
To better understand the deformation properties of soft clays under traffic loading with principal stress axis rotation, a corresponding investigation was performed in this study. A series of cyclic torsional shear tests on saturated soft clay simulating traffic loading were conducted through a GDS hollow cylinder apparatus. The influence of principal stress rotation on the development of permanent strain and pore pressure have been interpreted and discussed with their practical implications to analyze the effect of principal stress rotation on the mechanical properties of soil. Finally, a pore pressure model and a H-D backbone curve model were modified considering the principal stress rotation and cycles for the deformation behavior of soft clay under cyclic traffic loading.

\section{Specimen Preparation and Test Apparatus}

\subsection{Sampling Methods}

The soil samples were taken from the bottom of an approximately $10 \mathrm{~m}$ foundation pit in Wenzhou, China. To reduce the disturbance on the clay samples, thin-walled tubes (150 $\mathrm{mm}$ in diameter and $250 \mathrm{~mm}$ in length), uniformly coated with petroleum jelly, were slowly inserted into the bottom of the pit. Then, the thin-walled tubes were excavated carefully, sealed at both ends, and stored in a constant-temperature and -humidity chamber. The basic physical and mechanical indexes of the undisturbed soft clay used in the test were tested and are shown in Table 1 . In order to verify the quality of the clay samples, confined compression tests were carried out on the clay according to the method proposed by Lunne et al. [29]. The results showed that the clay samples in this study were less disturbed and could be classified as good to fair, as the same batch of tested samples used in previous research [1].

Table 1. Index properties of tested soft clay.

\begin{tabular}{cc}
\hline Basic Properties & Value \\
\hline Specific gravity $G_{s}\left(\mathrm{~g} / \mathrm{cm}^{3}\right)$ & $2.66-2.68$ \\
Natural density $\rho\left(\mathrm{g} / \mathrm{cm}^{3}\right)$ & $1.63-1.65$ \\
Natural water content $w(\%)$ & $56.7-59.6$ \\
Initial void ratio $e_{0}(-)$ & $1.64-1.71$ \\
Plasticity index $I_{p}(\%)$ & 42 \\
Plastic limit $w_{p}(\%)$ & 24 \\
Liquid limit $w_{L}(\%)$ & 66 \\
Clay content $(\%)$ & 55 \\
Silt content $(\%)$ & 41 \\
\hline
\end{tabular}

\subsection{Test Apparatus}

The test apparatus used was the GDS dynamic hollow cylindrical apparatus (DHCA) manufactured by GDS Instruments Ltd., UK. It can independently apply axial force $W$, torque $M_{\mathrm{T}}$, outer pressure $p_{0}$, and inner pressure $p_{i}$, and then control all four stress components in the soil element (axial stress $\sigma_{z}$, radial stress $\sigma_{r}$, tangential stress $\sigma_{\theta}$, and shear stress $\left.\tau_{z \theta}\right)$, i.e., the independent control of the magnitudes and directions of all three principal stresses. The apparatus also enables the customization of the cyclic loading waveforms for axial forces and torques. It enables continuous rotation of the principal stress axis and can be used to simulate traffic loading. Cai et al. [30] used a hollow cylinder apparatus to apply cyclic stress and shear stress to specimens, demonstrating that this method can simulate traffic loading better.

According to Hight et al. [31], the stress and strain components of the soil element in DHCA can be derived from the equations in Table 2. 
Table 2. Equations for data interpretation.

\begin{tabular}{cll}
\hline & \multicolumn{1}{c}{ Stress } & \multicolumn{1}{c}{ Strain } \\
\hline Vertical & $\sigma_{z}=\frac{W}{\pi\left(r_{o}^{2}-r_{i}^{2}\right)}+\frac{p_{o} r_{o}^{2}-p_{i} r_{i}^{2}}{\left(r_{o}^{2}-r_{i}^{2}\right)}$ & $\varepsilon_{z}=\frac{z}{H}$ \\
Circumferential & $\sigma_{r}=\frac{p_{o} r_{o}+p_{i} r_{i}}{r_{o}+r_{i}}$ & $\varepsilon_{\theta}=-\frac{u_{o}+u_{i}}{r_{o}+r_{i}}$ \\
Radial & $\sigma_{\theta}=\frac{p_{o} r_{o}-p_{i} r_{i}}{r_{o}-r_{i}}$ & $\varepsilon_{r}=-\frac{u_{o}-u_{i}}{r_{o}-r_{i}}$ \\
Shear & $\tau_{z \theta}=\frac{T}{2}\left[\frac{3}{2 \pi\left(r_{o}^{3}-r_{i}^{3}\right)}+\frac{4\left(r_{o}^{3}-r_{i}^{3}\right)}{3 \pi\left(r_{o}^{2}-r_{i}^{2}\right)\left(r_{o}^{4}-r_{i}^{4}\right)}\right]$ & $\gamma_{z \theta}=\frac{\theta\left(r_{o}^{3}-r_{i}^{3}\right)}{3 H\left(r_{o}^{2}-r_{i}^{2}\right)}$ \\
Major principal & $\sigma_{1}=\frac{\sigma_{z}+\sigma_{\theta}}{2}+\sqrt{\left(\frac{\sigma_{z}-\sigma_{\theta}}{2}\right)^{2}+\tau_{z \theta}^{2}}$ & $\varepsilon_{1}=\frac{\varepsilon_{z}+\varepsilon_{\theta}}{2}+\sqrt{\left(\frac{\varepsilon_{z}-\varepsilon_{\theta}}{2}\right)^{2}+\gamma_{z \theta}^{2}}$ \\
Intermediate principal & $\sigma_{2}=\sigma_{r}$ & $\varepsilon_{2}=\varepsilon_{r}$ \\
Minor principal & $\sigma_{3}=\frac{\sigma_{z}+\sigma_{\theta}}{2}-\sqrt{\left(\frac{\sigma_{z}-\sigma_{\theta}}{2}\right)^{2}+\tau_{z \theta}{ }^{2}}$ & $\varepsilon_{1}=\frac{\varepsilon_{z}+\varepsilon_{\theta}}{2}-\sqrt{\left(\frac{\varepsilon_{z}-\varepsilon_{\theta}}{2}\right)^{2}+\gamma_{z \theta}^{2}}$ \\
\hline
\end{tabular}

\section{Test Procedure}

First, the sample was slowly pushed out from the thin-walled tube with a special pusher and then cut to the desired size $(100 \mathrm{~mm}$ in outer diameter, $60 \mathrm{~mm}$ in inner diameter, and $200 \mathrm{~mm}$ in height) using a standard sample cutter. The soil cutter, cutting pedestal, and hollow cylindrical soil sample are shown in Figure 3. For detailed sample preparation principles and steps, refer to Shen et al. [32]. The specimen was then installed on the base of the DHCA. After the sample was installed, the test steps were loaded. At the beginning of the tests, the saturation phase with a $300 \mathrm{kPa}$ back pressure and $20 \mathrm{kPa}$ effective confining pressure on each specimen lasted for $24 \mathrm{~h}$ and was then followed by the B-check [1]. If $\mathrm{B}>0.97$, the specimen would then be consolidated at an effective confining pressure of $100 \mathrm{kPa}$ for approximately $48 \mathrm{~h}$, and the main consolidation would be considered complete when the change in the volume of specimen is less than $100 \mathrm{~mm}^{3}$ per hour. After that, under undrained conditions, the inner and outer confining pressure was kept constant, and the specimen was subjected to a cyclic loading with self-defined waveforms in axial force and torque. The loading waveforms are shown in Figure 4.

In order to distinguish the effect of cyclic stress level and different principal stress rotations, two indexes, the vertical cyclic stress ratio VCSR and the torsional cyclic stress ratio $\eta$, were used for definition, both of which are defined as follows:

$$
\begin{gathered}
\mathrm{VCSR}=\frac{\sigma_{\mathrm{z}}^{\mathrm{cyc}}}{2 p_{o}^{\prime}} \\
\eta=\frac{\tau_{\mathrm{z}}^{\mathrm{cyc}}}{\sigma_{\mathrm{z}}^{\mathrm{cyc}}}
\end{gathered}
$$

where $\sigma_{\mathrm{z}}^{\mathrm{cyc}}$ and $\tau_{\mathrm{z} \theta}^{\mathrm{cyc}}$ are the cyclic axial stress amplitude and the cyclic torsional shear stress amplitude, respectively, and $p_{o}^{\prime}$ is the initial mean principal stress. The increase in the torsional cyclic stress ratio $\eta$ indicates the increase in the principal stress axes rotation. If $\eta=0.00$, it is actually a cyclic triaxial test.

The test program is detailed in Table 3. Nine cyclic torsional shear tests were carried out at different values of VCSR and $\eta$. All tests were carried out with a loading frequency of $0.1 \mathrm{~Hz}$ and loaded up to 1000 cycles, with 50 data points recorded per cycle.

Table 3. Scheme of cyclic test.

\begin{tabular}{cccc}
\hline Shear Cyclic Stress Level, $\boldsymbol{\eta}$ & \multicolumn{3}{c}{ Vertical Cyclic Stress Ratio, VCSR } \\
\hline & Test1 & Test2 & Test3 \\
\hline 0.00 & 0.10 & 0.15 & 0.20 \\
0.25 & 0.10 & 0.15 & 0.20 \\
0.50 & 0.05 & 0.10 & 0.15 \\
\hline
\end{tabular}




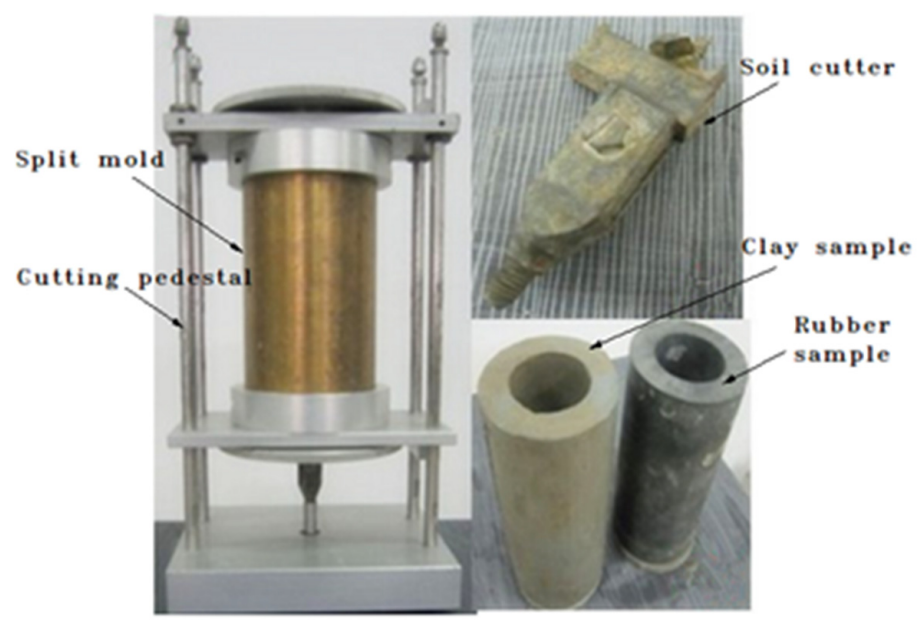

Figure 3. Method of making hollow cylindrical specimens.

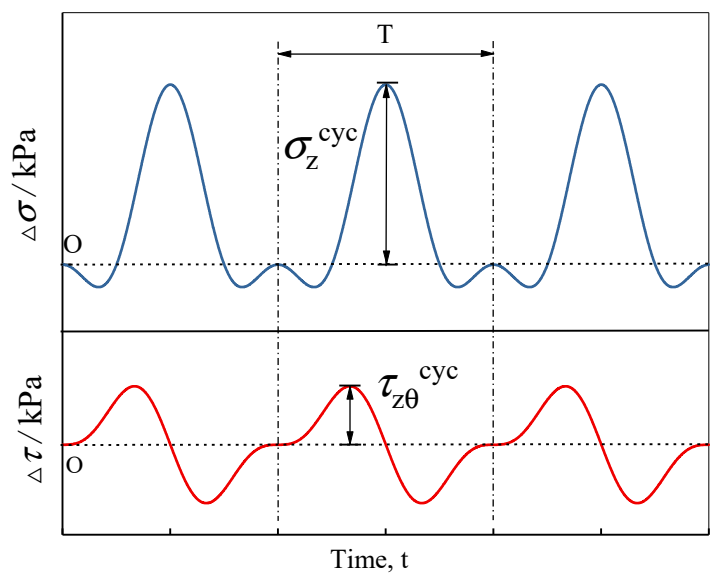

Figure 4. Diagram of loading waveforms.

\section{Test Results and Discussion}

\subsection{Pore Pressure}

Figure 5 shows the development of pore pressure with cycles $N$ under different loading conditions. As shown in Figure 5, the pore pressure accumulates rapidly in the early stage, slowing down in the later stage and eventually stabilizing. At the same torsional cyclic stress ratio $\eta$, the pore pressure accumulates more as the VCSR increases. At the same stress level, the increase in the degree of principal stress rotation also increased the pore pressure accumulation. In other words, the increase in both dynamic stress and the principal stress rotation can lead to an increase in the accumulated pore pressure. The development of pore pressure under cyclic loading is an important aspect of the change in the deformation strength of saturated soils. Dynamic pore pressure is also the key to analyzing the dynamic stability of soils. A correct understanding of the pore pressure development in saturated clay under cyclic loading and a suitable dynamic pore pressure model can be established to better analyze the dynamic characteristics of saturated soft clay. Based on the results of the round-trip triaxial and torsional shear tests, Sherif et al. [33] found that the rate of pore pressure growth at the Nth time and the intensity of the dynamic stresses have a linear relationship in double logarithmic coordinates, and the slope of the line does not vary significantly with cycle. As a result, Sherif et al. [33] proposed a dynamic pore pressure model for pore pressure growth under cyclic loading, which is given by:

$$
\Delta U_{N}=\left(1-U_{N-1}\right) \bar{N}\left(\frac{\tau_{N}}{\sigma_{N-1}^{\prime}}\right)^{\alpha}
$$




$$
\begin{aligned}
\Delta U_{N} & =U_{N}-U_{N-1} \\
\bar{N} & =\frac{C_{1} N}{N^{C_{2}}-C_{3}}
\end{aligned}
$$

where $U_{N}$ is the pore pressure after $N$ cycles; $U_{N-1}$ is the pore pressure after $N-1$ cycles; $\bar{N}$ is the cyclic effect; $\tau_{N}$ is the shear stress after $N$ cycles; $\sigma_{N-1}^{\prime}$ is the effective confining pressure after $N-1$ cycles; and $C_{1}, C_{2}, C_{3}$, and $\alpha$ are the test parameters, which depend on the soil properties and need to be determined by the tests.
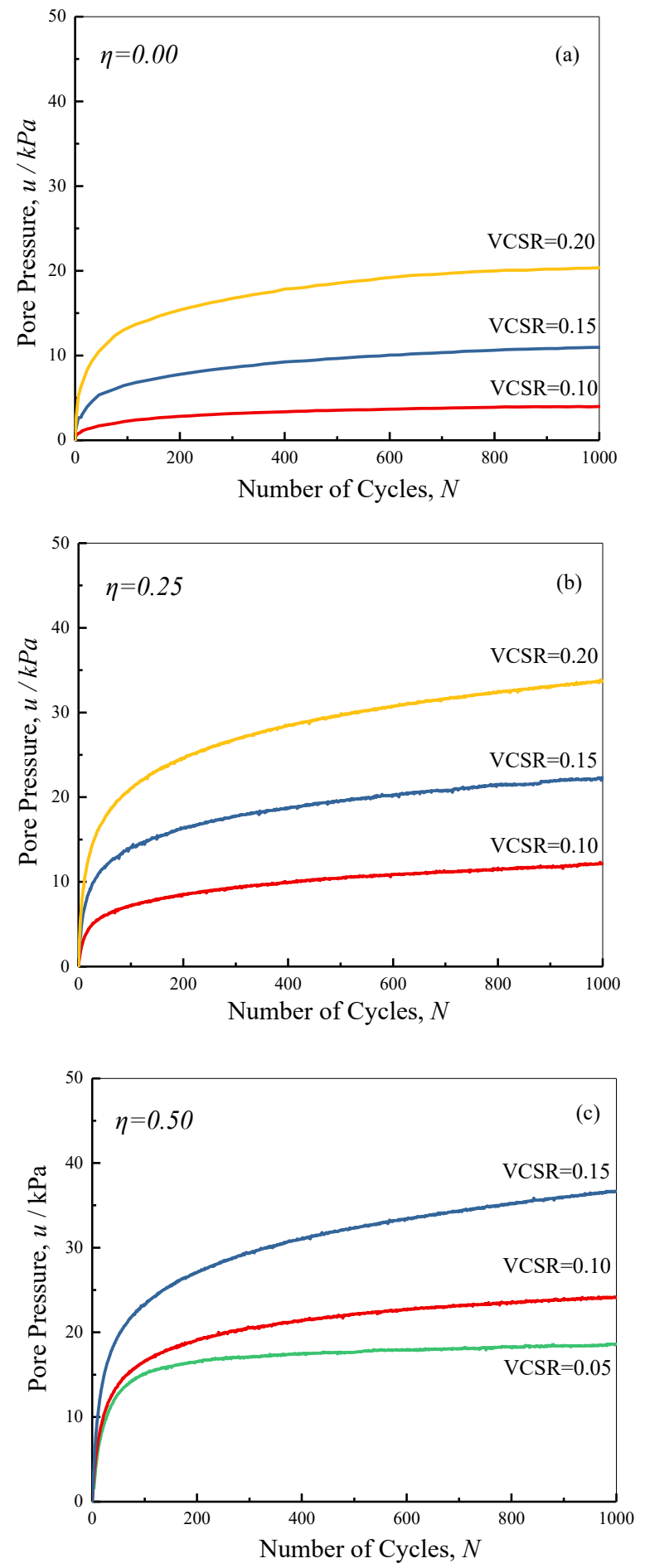

Figure 5. Pore pressure versus number of cycles under different cyclic loading: (a) $\eta=0.00$; (b) $\eta=0.25 ;$ (c) $\eta=0.50$. 
The soil unit under traffic loading is subjected to the continuous principal stress rotation, for which we propose a dynamic pore pressure correction model that considers the continuous principal stress rotation. Figure 6 shows the experimental relationship between the pore pressure parameter $\frac{\Delta U_{N}}{1-U_{N-1}}$ and the effective stress ratio $\frac{\tau_{N}}{\sigma_{N-1}^{\prime}}$, from which it can be seen that the pore pressure parameter increases with the effective stress ratio. In addition, the slope of each straight line shown in the graph is almost identical $(\alpha=1.13)$. It is also noted in Figure 6 that the increase in pore pressure during cyclic loading is also influenced by the stress cycles. In order to evaluate the effect of stress perimeter on pore pressure, the cyclic effect is introduced, which is derived from the curve equation fitted to the experimental data shown in Figure 7. The data in Figure 7 show that the pore pressure growth decreases with the number of cycles even if the amplitude of the dynamic stress is the same. Figure 8 shows the relationship between the pore pressure model parameters $C_{1}$, $C_{2}$, and $C_{3}$ and the torsional cyclic stress ratio $\eta$. The three parameters show a good linear relationship with the torsional cyclic stress ratio $\eta$, which can be expressed as follows:

$$
\begin{gathered}
C_{1}=-2.60 \eta+9.42 \\
C_{2}=1.22 \\
C_{3}=0.56 \eta+2.16
\end{gathered}
$$

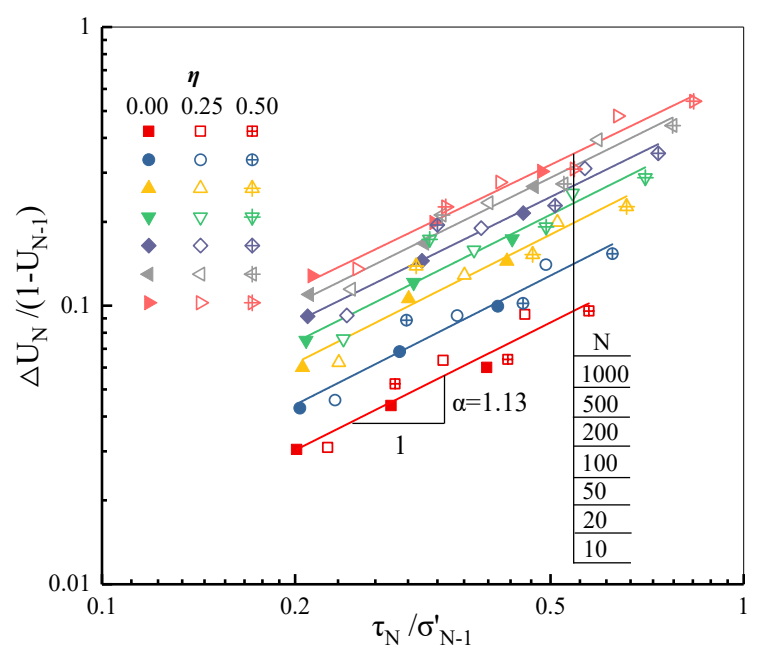

Figure 6. Pore pressure increase with different cycles.

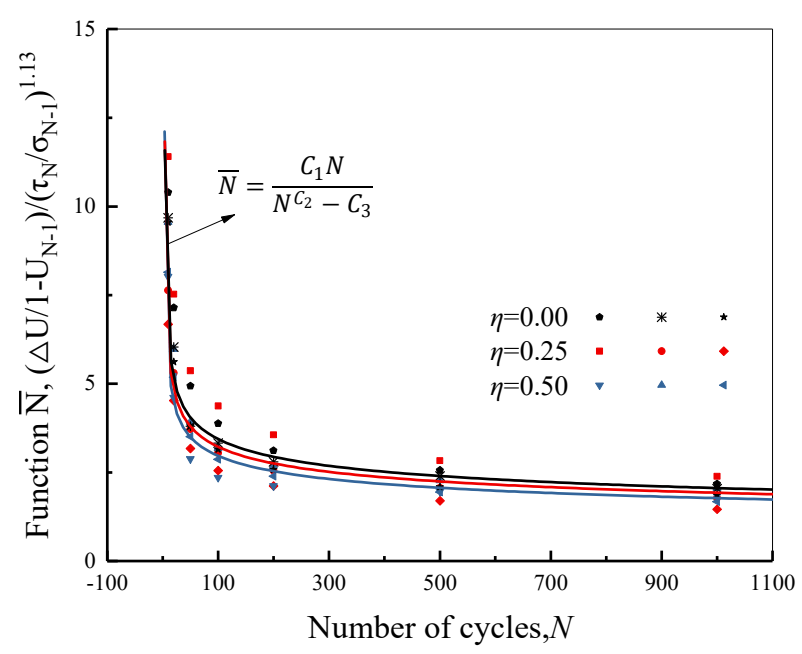

Figure 7. Cycles and functions $\bar{N}$. 


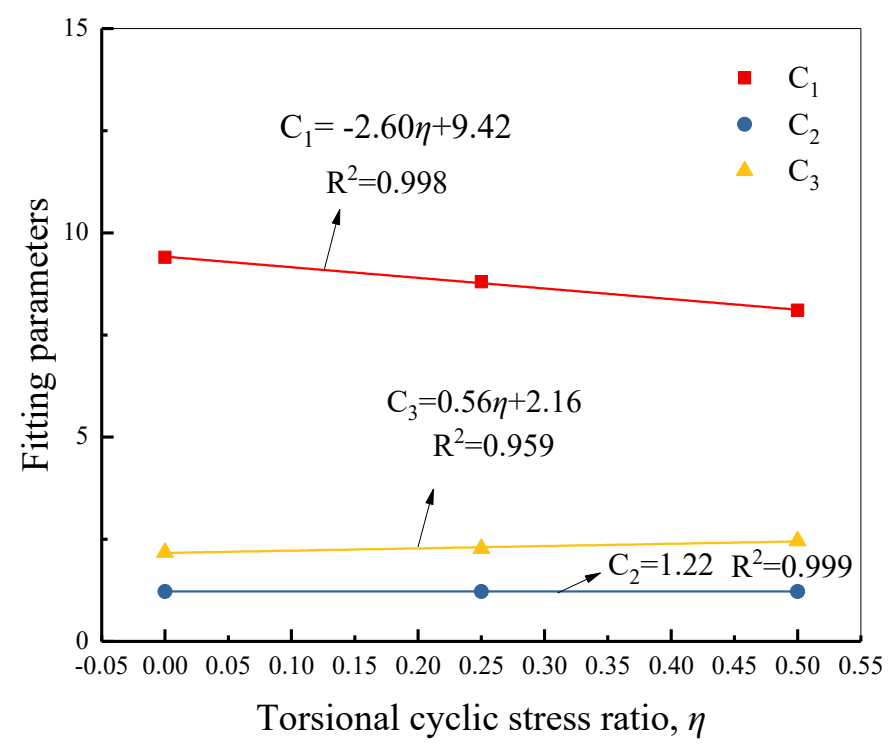

Figure 8. Relationship between parameters $C_{1}, C_{2}, C_{3}$, and $\eta$.

By substituting Equations (6)-(8) into Equation (3), a modified pore pressure model considering the continuous principal stress rotation can be developed as follows:

$$
\Delta U_{N}=\left(1-U_{N-1}\right) \frac{(-2.60 \eta+9.42) N}{N^{1.22}-0.56 \eta-2.16}\left(\frac{\tau_{N}}{\sigma_{N-1}^{\prime}}\right)^{1.13}
$$

Using the developed pore pressure model Equation (9), the test pore pressure under traffic loading considering the principal stress rotation was simulated. Figure 9 compares the pore pressure values derived from Equation (9) with the data measured from the test under cyclic loading. In this figure, the predicted results are in better agreement with the test results, proving that the dynamic pore pressure model is reasonable.

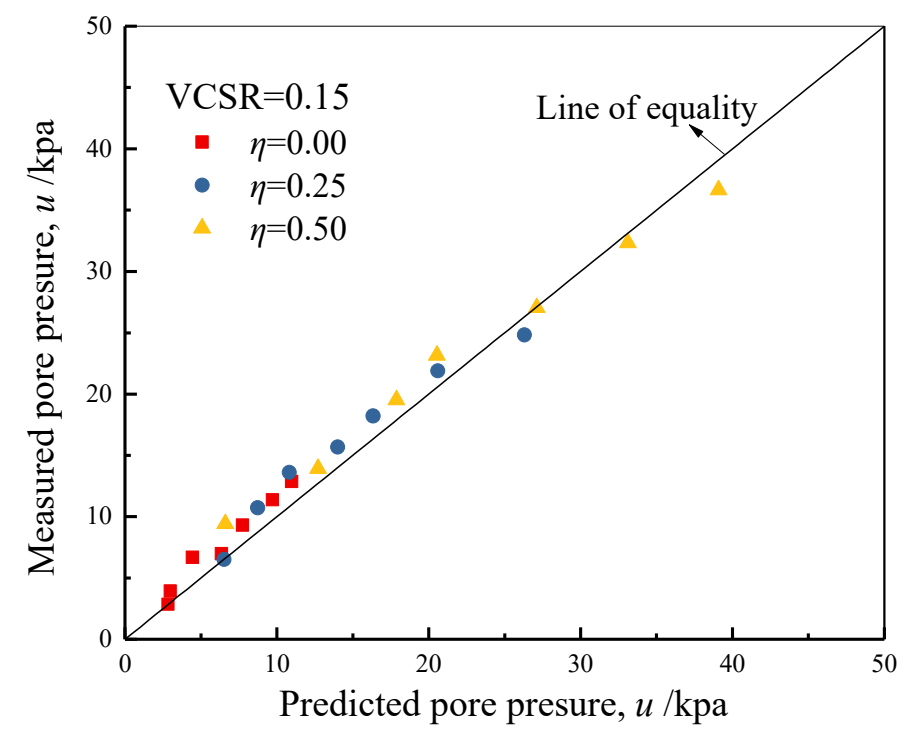

Figure 9. Comparison of predicted and measured pore pressure.

\subsection{Axial Strain}

Figure 10 shows the development of the permanent axial strain $\varepsilon_{z}{ }^{p}$ with loading cycles $N$ under different loading conditions. Similar to the cyclic triaxial test, the permanent strain in the specimen increases rapidly in the early stage, and most of the strain accumulation 
is completed within a short period. Then, the permanent strain growth rate gradually slows down. For common cyclic triaxial tests, the specimen under a higher VCSR value always has a larger permanent strain that is generated by the disturbance of the test. For the same VCSR, the specimen under a higher $\eta$ value also produces a higher permanent axial strain This indicates that even if the vertical stress levels are the same, the different rotations of the principal stress axes will still significantly affect the permanent axial strain in soft clay. For example, at $\eta=0.25$, the development of permanent strains in the tests corresponding to VCSR $=0.10, \mathrm{VCSR}=0.15$, and VCSR $=0.20$ increases in turn. Compared with the nonconsideration of the principal stress rotation, the rotation of the principal stress axis significantly aggravates the axial deformation of soil, and the axial deformation will continue to increase with the principal stress rotation, which indicates that the influence of the principal stress rotation on the soft clay cannot be ignored in the study of traffic loading.
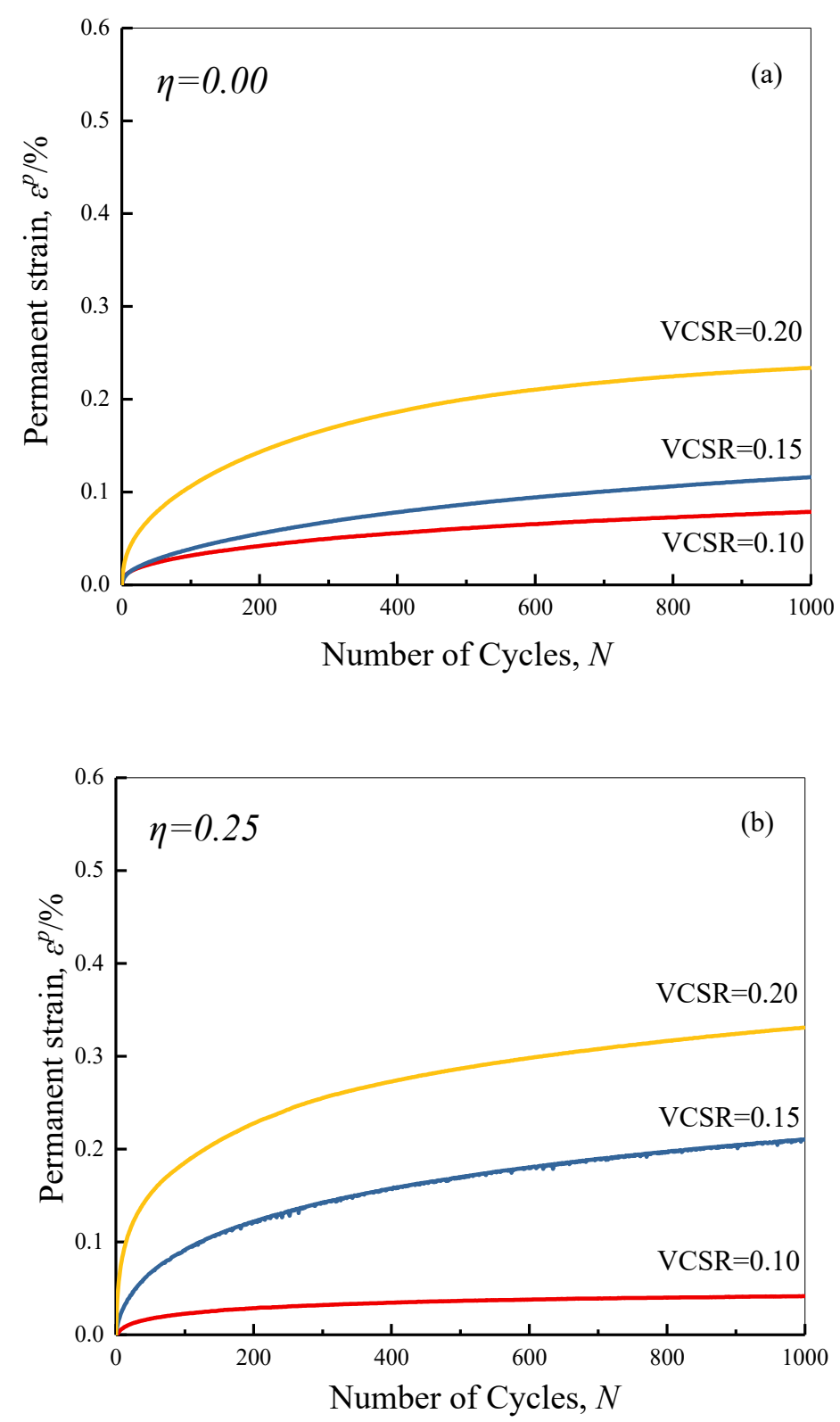

Figure 10. Cont. 


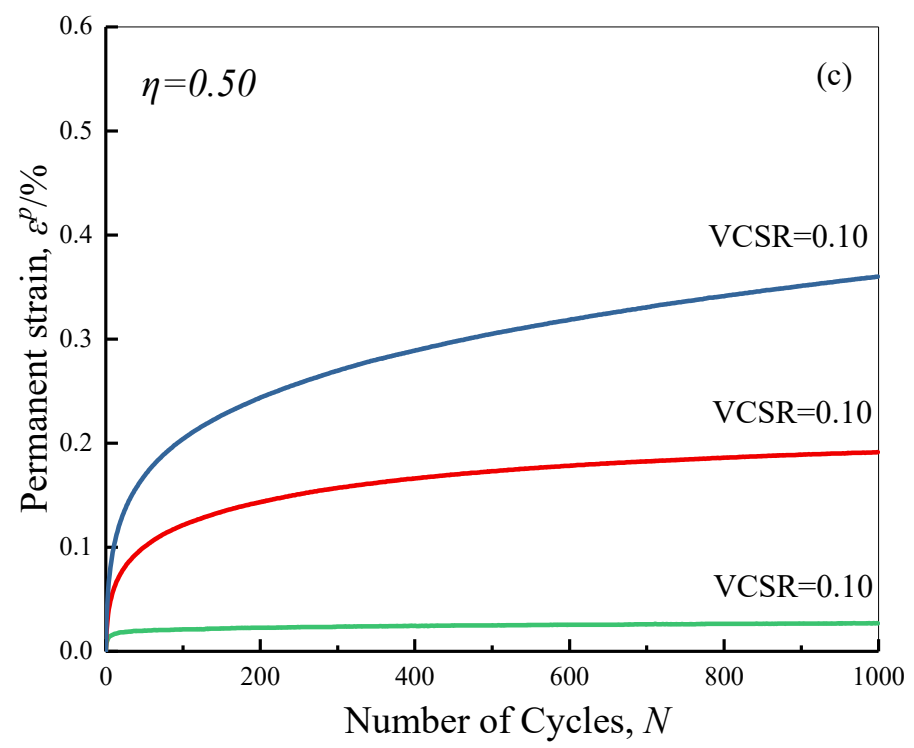

Figure 10. Axial dynamic strain versus number of cycles under different cyclic loading conditions: (a) $\eta=0.00 ;$ (b) $\eta=0.25$; (c) $\eta=0.50$.

\subsection{Stress-Strain Hysteresis Curve}

Taking specimen $(\eta=0.25$, VCSR $=0.20)$ for example, Figure 11 shows a typical stressstrain relationship curve under cyclic traffic loading. In order to eliminate the residual accumulated strain, the center of the hysteresis curve for the 1st, 10th, 100th, 500th, and 1000th cycles has been shifted to the origin. The hysteresis curves are relatively steep in the early loading stage, and the slope of the hysteresis circle gradually decreases with the number of cycles, indicating that there is stiffness degradation in the saturated soft clay under cyclic traffic loading. At the same time, due to the accumulation of pore pressure in the soil under undrained cyclic traffic loading, the permanent strain of the specimen has a positive correlation with cycles, which well reflects the nature of stiffness degradation of soft clay.

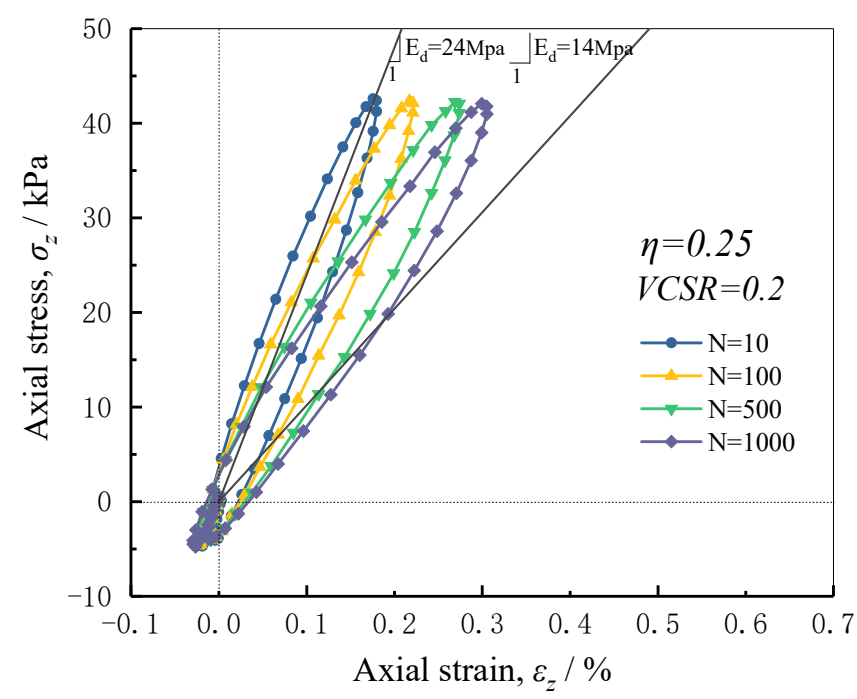

Figure 11. Comparison of typical stress-strain hysteresis curves at different cycles.

\subsection{Backbone Curve}

The backbone curve is the line at the top of the stress-strain curve for each loop of the soil subjected to different dynamic stress amplitudes. It represents the relationship between the maximum dynamic stress and strain, as shown in Figure 12. Under cyclic loading, the 
hysteresis loop is elongated, and the soil exhibits stiffness degradation. Therefore, there is no unique method for determining the backbone curve. The backbone curve is usually determined by taking the hysteresis loop data under the same number of loadings at each dynamic stress level. Zhang et al. [25] analyzed the hysteresis loops for different numbers of loops under the same cycle test. They proposed a dynamic backbone model that includes the dynamic stress amplitude, consolidation confining pressure, cycle number, and other influencing factors. Liao et al. [24] shifted the center of the hysteresis loops at a certain stress amplitude to the origin to eliminate the accumulated residual strain and then used the average value of all hysteresis loops (10 loops in total) to fit the backbone curve model. The backbone curve model used by the above authors is the modified Hardin-Drnevich model, which is often used to construct backbone curves for soft clay, i.e., the modification of the parameters of the H-D model.

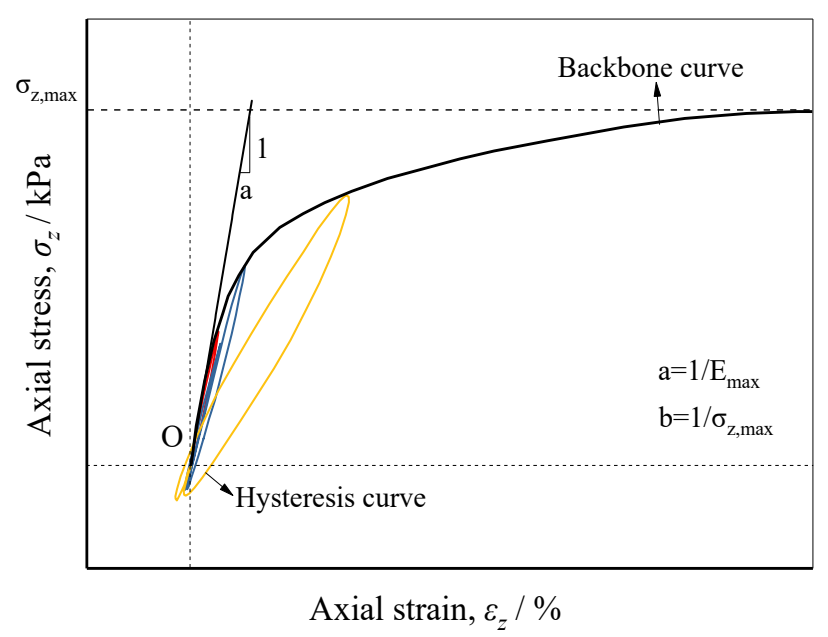

Figure 12. Schematic diagram of stress-strain backbone curve.

The H-D model is usually expressed as a hyperbolic type, that is,

$$
\sigma_{\mathrm{z}}^{\mathrm{cyc}}=\frac{\varepsilon_{\mathrm{z}, \mathrm{r}}}{a+b \varepsilon_{\mathrm{z}, \mathrm{r}}}
$$

where $\sigma_{\mathrm{z}}^{\mathrm{cyc}}$ and $\varepsilon_{\mathrm{z}, \mathrm{r}}$ denote the dynamic stress amplitude and resilient strain $\left(\varepsilon_{\mathrm{z}, \mathrm{r}}\right.$ is the recoverable portion of axial strain, i.e., the difference between the maximum strain and the strain at the end of the specific loading cycle), respectively, and $a$ and $b$ are test-related parameters, where a is the reciprocal of the maximum resilient modulus $\frac{1}{E_{\max }}$ and $b$ is the reciprocal of the ultimate dynamic stress of the soil $\frac{1}{\sigma_{z, \max }}$ [22], as shown in Figure 12.

Figure 13 shows the backbone curve model for different cycles with different degrees of principal stress rotation. The backbone curve has a typical hyperbolic type. As the number of cycles increases, the backbone curve shifts to the left, the initial slope decreases, and the backbone curve pattern stabilizes. This indicates that the stiffness of the soft clay decreases with the number of cycles. After the backbone curve shape has gradually stabilized, it is found that with the increase in the principal stress rotation, the backbone curve lowers. This indicates that the effect of the principal stress rotation significantly weakens the dynamic properties of the soft clay. Equation (10) is used to fit the curve. The results are in good agreement with the original test data. The values of the backbone curve equations for the different number of cycles with different torsional cyclic stress ratios $\eta$ are shown in Table 4. 

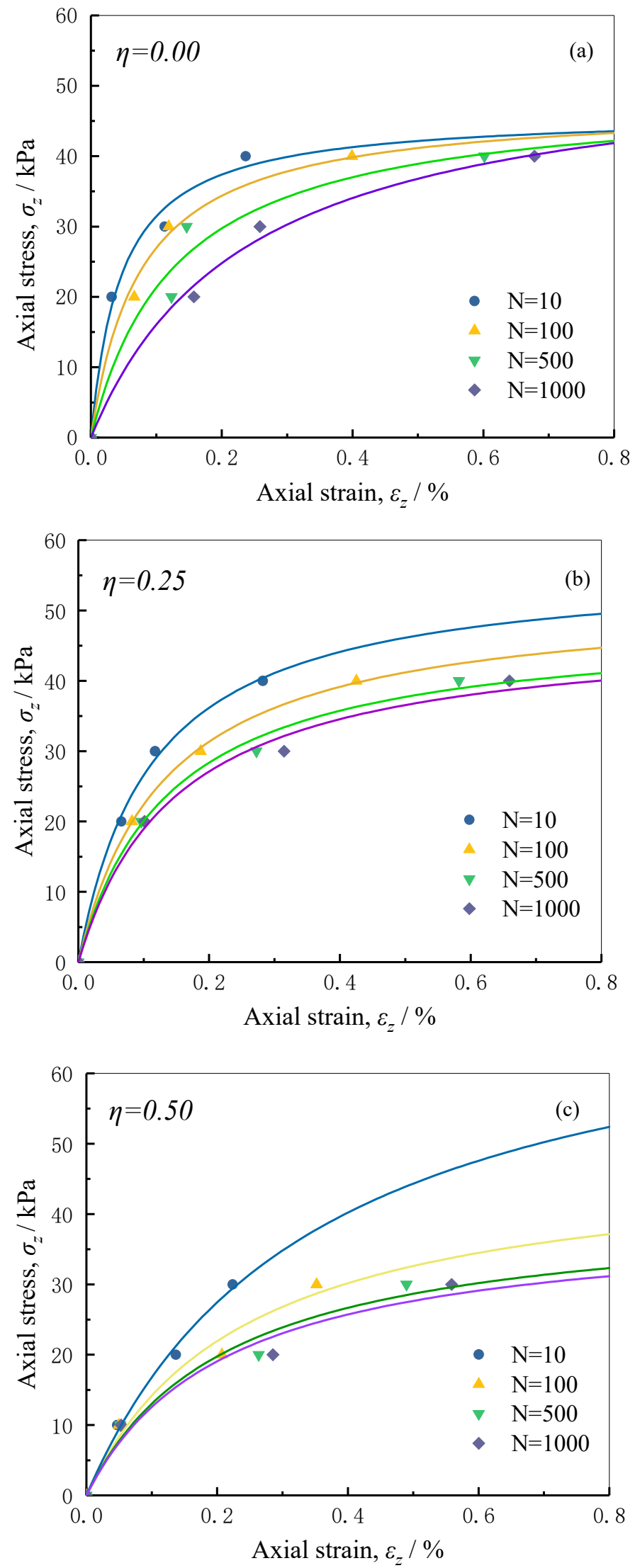

Figure 13. Backbone curves with different $\eta$ under different cycles: (a) $\eta=0.00$; (b) $\eta=0.25$; (c) $\eta=0.50$ 
Table 4. Fitting parameters.

\begin{tabular}{ccccc}
\hline No. of Cycles, $\boldsymbol{N}$ & Parameter, $\boldsymbol{a}$ & Parameter, $\boldsymbol{b}$ & R-Squared, $\boldsymbol{R}^{\mathbf{2}}$ & $\begin{array}{c}\text { Cyclic Shear Stress } \\
\text { Ratio, } \boldsymbol{\eta}\end{array}$ \\
\hline 10 & 0.00101 & 0.0217 & 0.9462 & \\
100 & 0.00160 & 0.0211 & 0.9717 & 0.00 \\
500 & 0.00265 & 0.0204 & 0.8441 & \\
1000 & 0.00439 & 0.0184 & 0.9717 & \\
10 & 0.00199 & 0.0177 & 0.9890 & \\
100 & 0.00254 & 0.0192 & 0.9883 & \\
500 & 0.00291 & 0.0207 & 0.9761 & 0.50 \\
1000 & 0.00318 & 0.0210 & 0.9647 & \\
\hline 10 & 0.00463 & 0.0133 & 0.9860 & \\
100 & 0.00498 & 0.0207 & 0.9487 & \\
500 & 0.00524 & 0.0244 & 0.9350 & \\
1000 & 0.00543 & 0.0253 & 0.9338 & \\
\hline
\end{tabular}

In order to study the deformation characteristics of soft clay under traffic loading with principal stress axis rotations, the torsional cyclic stress ratio $\eta$ and cycles $N$ were fitted to the parameters $a$ and $b$, and it was found that $a$ and $b$ simultaneously satisfy the following relation:

$$
a=p_{1}+p_{2} * \eta^{3}+p_{3} * \ln (N)
$$

where $p_{1}=0.00098, p_{2}=0.02103$, and $p_{3}=0.00024$;

$$
b=p_{4}+p_{5} * \eta^{3}+p_{6} * \ln (N)
$$

where $p_{4}=0.01508, p_{5}=-0.00725$, and $p_{6}=0.00143$

Substituting Equations (11) and (12) into Equation (10), a modified H-D backbone curve model considering cycles and principal stress rotations can be developed as follows:

$$
\sigma_{\mathrm{z}}^{\mathrm{cyc}}=\frac{\varepsilon_{\mathrm{z}, \mathrm{r}}}{0.00098+0.02103 \eta^{3}+0.00024 \ln (N)+\left(0.01508-0.00725 \eta^{3}+0.00143 \ln (N)\right) \varepsilon_{\mathrm{z}, \mathrm{r}}}
$$

To verify this model, the results for three cyclic tests with VCSR $=0.15$ were used. Figure 14 shows the results of this H-D backbone curve model compared with the measured test data, and the predicted results are in good agreement with the measured data. The results show that the predicted value is larger than the measured value. The deviation between the predicted value and the measured value is less than $14 \%$ when the principal stress rotation is taken into account, while the deviation between the predicted value and the measured value is as high as $42 \%$ if the principal stress axis rotation is not taken into account. This modified model improves the prediction accuracy by a factor of three, demonstrating the accuracy of our model and the need to account for principal stress axis rotation for traffic loading. In the actual engineering, each structure must achieve a certain safety factor; the predicted values are on the high side to better meet this need for practical engineering and to ensure engineering safety. The real stress conditions in the pavement are much more complicated. This modified model can provide a preliminary reference for pavement design.

Compared with the conventional H-D backbone curve model, the model constructed in the paper considers the effects of both the number of cycle turns and the torsional cyclic stress ratio $\eta$. As a result, the model can better represent the stiffness degradation characteristics of soft clay under traffic loading and is more realistic. 


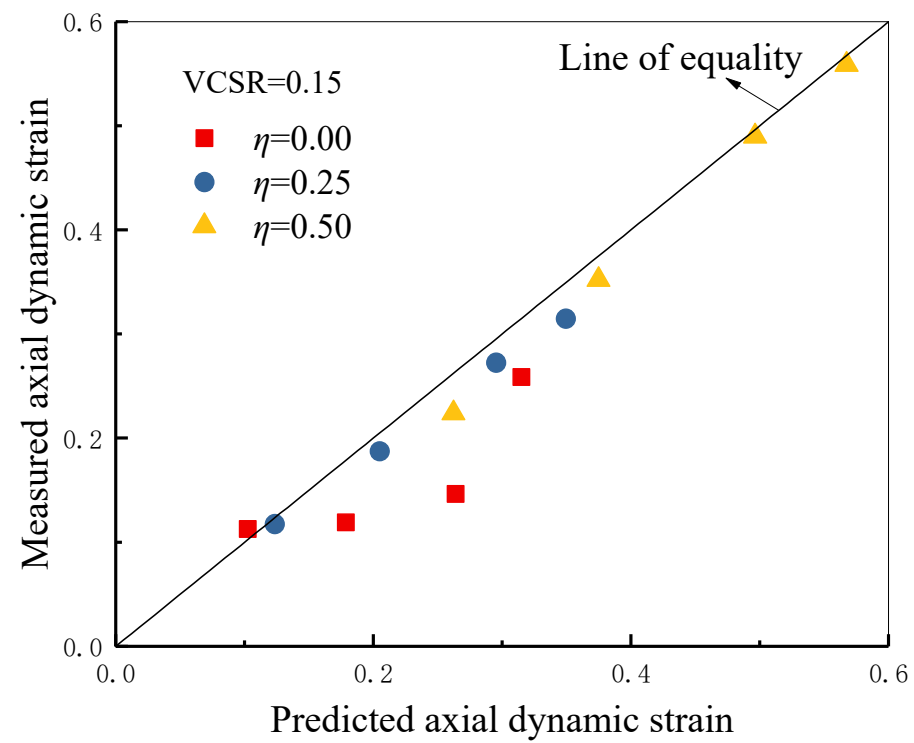

Figure 14. Comparison of predicted and measured axial dynamic strain.

\section{Conclusions}

To study the deformation characteristics of soft clay under traffic loading with the continuous principal stress rotation, a series of cyclic HCA tests were conducted on Wenzhou soft clay under different torsional cyclic stress ratios and degrees of principal stress rotation. The conclusions are summarized as follows:

(1) The continuous rotation of the principal stress axis could be controlled by dynamic hollow cylinder torsional shear apparatus (DHCA) to simulate traffic loading. Compared with the traditional triaxial test without considering the principal stress rotation, the rotation of the principal stress axis would aggravate the axial deformation of soil samples. Therefore, the influence of the principal stress rotation must be considered in the prediction of settlement and stability for pavement engineering suffering traffic loading.

(2) Changes in the vertical cyclic stress ratio VCSR and torsional cyclic stress ratio $\eta$ had a more pronounced effect on the dynamic mechanical properties of soft clay. Under the traffic loading, the permanent strain and pore pressure increased with the increments in VCSR and $\eta$, and there was stiffness degradation of the soil.

(3) A modified pore pressure model considering the rotation of the principal stress was proposed, and the relationship between the growth of pore pressure and cycles considering the effect of the principal stress rotation was established. The reasonableness of the model was confirmed by predicting the growth of the accumulated pore pressure under different cycles.

(4) The permanent strain and pore pressure showed an overall increasing trend with the number of cycles, but both tended to stabilize with cycles. At the same time, the slope of the backbone curve of saturated soft clay decreased, and the stiffness of the soil decreased.

(5) The traditional H-D backbone curve model without considering the continuous rotation of the principal stress axis under traffic load was modified, and the modified $\mathrm{H}-\mathrm{D}$ backbone curve model considering the continuous rotation of the principal stress axis was established. Compared with the traditional H-D backbone curve model, the prediction accuracy of the modified model is significantly improved, which can provide some guidance for pavement design. 
Author Contributions: Conceptualization, Z.F.; methodology, Z.F., G.W. and W.S.; software, G.W. and W.S.; validation, Z.F. and G.W.; formal analysis, W.S.; investigation, Z.F.; resources, Y.Y. and W.S.; data curation, Y.Y. and P.W.; writing-original draft preparation, Y.Y., T.W. and P.W.; writing-review and editing, Z.F., T.W. and G.W.; visualization, T.W. and P.W.; supervision, Z.F. and P.W.; project administration, Z.F. and T.W.; funding acquisition, Z.F. All authors have read and agreed to the published version of the manuscript.

Funding: The work presented in this paper was financially supported by the Natural Science Foundation of Zhejiang Province (grant numbers LQ21E080015).

Institutional Review Board Statement: Not applicable.

Informed Consent Statement: Not applicable.

Data Availability Statement: The data used to support the findings of this study can be obtained from the corresponding author upon request.

Conflicts of Interest: The authors declare no conflict of interest.

\section{References}

1. Guo, L.; Wang, J.; Cai, Y.; Liu, H.; Gao, Y.; Sun, H. Undrained Deformation Behavior of Saturated Soft Clay under Long-Term Cyclic Loading. Soil Dyn. Earthq. Eng. 2013, 50, 28-37. [CrossRef]

2. Skempton, A.W. The Pore-Pressure Coefficients A and B. Géotechnique 1954, 4, 143-147. [CrossRef]

3. Ishikawa, T.; Sekine, E.; Miura, S. Cyclic Deformation of Granular Material Subjected to Moving-Wheel Loads. Can. Geotech. J. 2011, 48, 691-703. [CrossRef]

4. Tang, L.; Chen, H.; Sang, H.; Zhang, S.; Zhang, J. Determination of Traffic-Load-Influenced Depths in Clayey Subsoil Based on the Shakedown Concept. Soil Dyn. Earthq. Eng. 2015, 77, 182-191. [CrossRef]

5. Powrie, W.; Yang, L.A.; Clayton, C.R.I. Stress Changes in the Ground below Ballasted Railway Track during Train Passage. Proc. Inst. Mech. Eng. Part F J. Rail Rapid Transit 2007, 221, 247-262. [CrossRef]

6. Sanger, F.J.; Sayles, F.H. Thermal and Rheological Computations for Artificially Frozen Ground Construction. Eng. Geol. 1979, 13, 311-337. [CrossRef]

7. Shahu, J.T.; Yudhbir; Rao, N. A Simple Test Methodology for Soils under Transportation Routes. Geotechnique 1999, 49, 639-649. [CrossRef]

8. Yasuhara, K.; Murakami, S.; Song, B.-W.; Yokokawa, S.; Hyde, A.F.L. Postcyclic Degradation of Strength and Stiffness for Low Plasticity Silt. J. Geotech. Geoenviron. Eng. 2003, 129, 756-769. [CrossRef]

9. Dobry, R.; Vucetic, M. Dynamic Properties and Seismic Response of Soft Clay Deposits. In Proceedings of the International Symposium on Geotechnical Engineering of Soft Soils, Mexico City, Mexico, 13-14 August 1987; Volume 2, pp. 51-87.

10. Stokoe, K.H., II; Hwang, S.K.; Lee, J.K.; Andrus, R.D. Effects of Various Parameters on the Stiffness and Damping of Soils at Small to Medium Strains. Pre-failure Deformation of Geomaterials. In Proceedings of the International Symposium, Sapporo, Japan, 12-14 September 1994.

11. Teachavorasinskun, S.; Thongchim, P.; Lukkunaprasit, P. Stress Rate Effect on the Stiffness of a Soft Clay from Cyclic, Compression and Extension Triaxial Tests. Géotechnique 2002, 52, 51-54. [CrossRef]

12. Matešić, L.; Vucetic, M. Strain-Rate Effect on Soil Secant Shear Modulus at Small Cyclic Strains. J. Geotech. Geoenviron. Eng. 2003, 129, 536-549. [CrossRef]

13. Vucetic, M. Cyclic Threshold Shear Strains in Soils. J. Geotech. Eng. 1994, 32, 2208-2228. [CrossRef]

14. Khosla, V.K.; Singh, R.D. Influence of Number of Cycles on Strain. Can. Geotech. J. 2011, 15, 584-592. [CrossRef]

15. Paul, M.; Sahu, R.B.; Banerjee, G. Undrained Pore Pressure Prediction in Clayey Soil under Cyclic Loading. Int. J. Geomech. 2015, 15, 04014082. [CrossRef]

16. Ohara, S.; Matsuda, H. Study on the Settlement of Saturated Clay Layer Induced by Cyclic Shear. Soils Found. 1988, 28, 103-113. [CrossRef]

17. Li, T.; Meissner, H. Two-Surface Plasticity Model for Cyclic Undrained Behavior of Clays. J. Geotech. Geoenviron. Eng. 2002, 128, 613-626. [CrossRef]

18. Moses, G.G.; Rao, S.N. Degradation in Cemented Marine Clay Subjected to Cyclic Compressive Loading. Mar. Georesour. Geotechnol. 2010. [CrossRef]

19. Hardin, B.; Drnevich, V. Shear Modulus and Damping in Soil: Measurement and Parameter Effects. J. Soil Mech. Found. Eng. ASCE 1972, 98, 603-624. [CrossRef]

20. Hardin, B.; Drnevich, V. Shear Modulus and Damping in Soils: Design Equations and Curves. J. Soil Mech. Found. Div. 1972, 98. [CrossRef]

21. Ishibashi, I.; Zhang, X. Unified Dynamic Shear Moduli and Damping Ratios of Sand and Clay. Soils Found. 1993, 33, 182-191. [CrossRef] 
22. Sun, L.; Cai, Y.; Gu, C.; Wang, J.; Guo, L. Cyclic deformation behaviour of natural $\mathrm{K}_{0}$-consolidated soft clay under different stress paths. J. Cent. South Univ. 2015, 22, 4828-4836. [CrossRef]

23. Pyke, R.M. Nonlinear Soil Models for Irregular Cyclic Loadings. Int. J. Rock Mech. Min. Sci. Geomech. Abstr. 1979, 16, 127. [CrossRef]

24. Liao, H.J.; Tao, L.I.; Zong-Yuan, M.A.; Liu, J. Comparative Analysis of Backbone Curve Models for Loess Soils. Rock Soil Mech. 2009, 30, 17-21.

25. Zhang, Y.; Kong, L.W.; Li, X.W. Dynamic Backbone Curve Model of Saturated Soft Clay under Cyclic Loading. Yantu Lixue/Rock Soil Mech. 2010, 31, 1699-1704+1708.

26. Huang, J.; Chen, J.; Lu, Y.; Yi, S.; Cui, L. Deformation Behaviors and Dynamic Backbone Curve Model of Saturated Soft Clay under Bidirectional Cyclic Loading. Int. J. Geomech. 2020, 20, 04020016. [CrossRef]

27. Hardin, B.O.; Kalinski, M.E. Estimating the Shear Modulus of Gravelly Soils. J. Geotech. Geoenviron. Eng. 2005, 131, 867-875. [CrossRef]

28. Martin, P.P.; Boltonseed, H. One-Dimensional Dynamic Ground Response Analyses: J Geotech Engng Div ASCE, V108, NGT7, July 1982, P935-952. Int. J. Rock Mech. Min. Sci. Geomech. Abstr. 1983, 20, A9. [CrossRef]

29. Lunne, T.; Berre, T.; Andersen, K.H.; Strandvik, S.; Sjursen, M. Effects of Sample Disturbance and Consolidation Procedures on Measured Shear Strength of Soft Marine Norwegian Clays. Can. Geotech. J. 2006, 43, 726-750. [CrossRef]

30. Cai, Y.; Wu, T.; Guo, L.; Wang, J. Stiffness Degradation and Plastic Strain Accumulation of Clay under Cyclic Load with Principal Stress Rotation and Deviatoric Stress Variation. J. Geotech. Geoenviron. Eng. 2018, 144, 04018021. [CrossRef]

31. Hight, D.W.; Symes, M.J.; Gens, A. The Development of a New Hollow Cylinder Apparatus for Investigating the Effects of Principal Stress Rotation in Soils. Geotechnique 1983, 33, 355-383. [CrossRef]

32. Zhou, J.; Zhang, J.L.; Shen, Y.; Zhang, Q.F. Preparation of Hollow Cylindrical Samples of Intact Soft Clay. Chin. J. Geotech. Eng. 2007. [CrossRef]

33. Ishibashi, I.; Sherif, M.A.; Student, C.T.F. Pore-Pressure Rise Mechanism and Soil Liquefaction. Soils Found. 1977, 17, 17-27. [CrossRef] 